\title{
LA DENOMINACIÓN DEL GOBERNANTE EN LOS HISTORIADORES LATINOS DE LA ANTIGÜEDAD TARDÍA. ESTUDIO LÉXICO*
}

\author{
A MARÍA JOSÉ LÓPEZ DE AYALA \\ IN MEMORIAM
}

El presente artículo se centra en el análisis del vocabulario con que se designa al gobernante en las obras De summa temporum uel de origine actibusque gentis Romanorum y De rebus Geticis de Jordanes y la Historia Francorum de Gregorio de Tours. En primer lugar se analizan los términos augustus, augusta, caesar e imperator, denominaciones del gobernante del Imperio Romano, después princeps, que hace refencia tanto al Romano como al de otros pueblos, a continuación rex, regi$n a$, que siguen siendo los vocablos con que se nombra a los reyes romanos $\mathrm{y}$, además, designan al máximo mandatario de otros pueblos. Este mismo valor, pero restringido a monarcas de pequeños estados, tienen términos menos frecuentes en época clásica, como regnator y regulus y otros de aparición más tardía como subregulus y regalis. Algunos de estos términos acabaron desapareciendo, pero muchos perviven en las lenguas modernas.

Palabras-clave: gobernante; Jordanes; Gregorio de Tours; augustus; augusta; caesar e imperator; rex; regina; regnator; regulus; subregulus; regalis.
MATILDE CONDE SALAZAR (CSIC)

CRISTINA MARTÍN PUENTE (UCM)

This paper studies the vocabulary to designate a governor in Jordanes' De summa temporum uel de origine actibusque gentis Romanorum and De rebus Geticis and in Gregorius of Tours' Historia Francorum. Firstly, the terms augustus, augusta, caesar and imperator are analised; then princeps, that refers both to the Roman one and to that of other people; next, rex, regina, which keep being the terms to name Roman kings and, besides, designate the leader of other people. This same value, but restricted to monarches of smaller states, has less frequent terms in the Clasical age, such as regnator and regulus, and later ones such as subregulus and regalis. Some of these terms ended up dissapearing, but many of them have survived in modern languages.

Keywords: ruler; Iordanes; Gregorius Turonensis; augustus; augusta; caesar e imperator; rex; regina; regnator; regulus; subregulus; regalis.

\section{Introducción y objetivos}

El profundo cambio de régimen político y social que la llegada al poder

* Este artículo forma parte del Proyecto de Investigación DGYCIT (PS98-0664), en el que tratamos de desarrollar la hipótesis de que en la Antigüedad Tardía, debido a una serie de cambios socio-políticos, hay un cambio en la norma lingüística latina.

EMERITA. Revista de Lingüística y Filología Clásica (EM) — LXXII 2, 2004 
de Julio César provoca en Roma convierte la antigua República en una monarquía cada vez más absoluta. Respecto a la religión, un culto oficial pagano convive con distintas sectas que llegan a Roma entre las cuales el cristianismo va tomando cada vez más fuerza hasta el punto de que los emperadores lo ven como una amenaza y comienzan a perseguir a sus seguidores. Con el tiempo el cristianismo acabará siendo religión oficial del Imperio ${ }^{1}$. Por otro lado, también se transforma la relación con los pueblos bárbaros que desde hacía tiempo se estaban asentando en territorio del Imperio Romano (Paschoud, 1998). Todo ello se plasma necesariamente en el léxico de los historiadores latinos tardíos, que al ser cristianos tienen en buena medida la Biblia y a los Padres de la Iglesia como modelo ${ }^{2}$. Ni el Thesaurus Linguae Latinae (ThLL), ni los diccionarios y léxicos clásicos o medievales suelen recoger con rigor las novedades léxicas de la 'tierra de nadie' que es, en ese aspecto, la Antigüedad Tardía. Tampoco existen obras lexicográficas de conjunto específicas para este vocabulario, de ahí la pertinencia de los estudios sobre este léxico.

Recientemente ${ }^{3}$ hemos examinado los verbos que expresan el acceso a un cargo, por elección o nombramiento, en Gregorio de Tours y Jordanes, precursores en gran medida de la Alta Edad Media. Así hemos comprobado que los dos historiadores cristianos - ambos del s. VI y con una lengua muy parecida, como señala Bonnet (1890:84) - siguen utilizando las formas clásicas típicas como facere, eligere, constituere, creare, efficere o conlocare. Pero, cuando hablan de su propio tiempo, sobre el cual apenas tienen fuentes escritas, prefieren formas como accedere, adsciscere, obtinere, ordinare y sortiri - para referirse a cargos tanto civiles como eclesiásticos -, destinare, eleuare, sumere y adsumere - exclusivamente para cargos políticos - y consecrare - exclusivamente para los cargos eclesiásticos -, verbos que muchas veces tienen esa misma acepción en la Biblia latina, los Padres de la Iglesia y los autores cristianos en general, mejor conocidos por ellos que los autores clásicos. Algunos de estos verbos conservan en las lenguas modernas la acepción que adquieren en época tardía. Por ejemplo, en español $a c$ ceder, consagrar, destinar, elevar y ordenar. También hemos estudiado, en estos mismos autores, las distintas denominaciones de algunos funcionarios

1 Cf. Cameron 1998, pp. 21-22; Hague 1988; Kelly 1998; Matthews 2000; McCormick 2000; Michael 2000;

2 Sobre las características de esta lengua es interesante consultar los trabajos de Mohrmann 1961c, 1961b, pp. 91 y 101, 1961f, p. 137, 1961d, 1961e y 1961 a, p. 123 ss.

3 Cf. Conde Salazar-Martín Puente (en prensa a). 
o cargos del imperio y de las cortes de las diferentes naciones que se han asentado y se han ido afianzando dentro de las fronteras del imperio (consiliarius, patricius, comes, comes stabuli, dux, minister, cubicularius, maior domus y camerarius), términos que han sobrevivido en la lengua española en las formas consejero, patricio, conde, condestable, duque, ministro, cubiculario, mayordomo y camarero ${ }^{4}$.

En esta ocasión, continuando con el análisis del campo léxico del poder en estos mismos autores, nos centraremos en el vocabulario con que se designa al gobernante en las obras De summa temporum uel origine actibusque gentis Romanorum (Iord. Rom.) y De rebus Geticis (Iord. Get.) de Jordanes y la Historia Francorum Gregorio de Tours (Greg.) ${ }^{5}$. En primer lugar analizaremos augustus, augusta, caesar e imperator, denominaciones de quien está a la cabeza del Imperio Romano, después princeps, que hace referencia tanto al dirigente romano como al de otros pueblos, a continuación rex, regina, que siguen siendo los vocablos con que se nombra a los reyes romanos y, además, designan al máximo mandatario de otros pueblos. El mismo valor tienen términos menos frecuentes en época clásica, como regnator y regulus y los de aparición más tardía subregulus y regalis ${ }^{6}$.

\section{El Emperador Romano}

\subsection{Caesar}

Como recogen el ThLL (Nomina propria latina, Supplementum I, s.v., cols. 34-36), el Lexicon des Mittelalters (s.v., vol. II, cols.1351-1353) y el

4 Cf. Conde Salazar-Martín Puente (en prensa b).

5 Seguimos la edición del CD-ROM eMGH-3.

6 En Jordanes y Gregorio, al igual que en otros historiadores como Orosio, encontramos también el vocablo tyrannus, término clásico, documentado en Cicerón y Livio, que designa, como en griego, al monarca o soberano (cf. Isid. Orig. 9.3), empleado para referirse incluso a algunos de los que son considerados emperadores como Eugenio o Juan. Cf: «A consubrino Theodosio imperatorem fuisse creatum et apud urbem Romam tyrannum Iohannem in imperium surrexisse (...) adiecit» (Greg. 2.8); «Maximum autem tyrannum, qui Gratianum interficerat et sibi Gallias vindicabat, apud Mediolanum, una cum Valentiniano imperatore adgrediens ab Oriente, clausit cepit occidit» (Iord. Rom. 316); «Imperator ...contra Eugenium tyrannum, plus quam XX milia armatorum ... secum duxit uictoriaque de praedicto tyranno potitus ultionem exegit» (Iord. Get. 28.145). No entraremos en el análisis de este término porque en su significado prima sobre todo la idea de usurpación ilegítima (cf. Isid. Orig. 1.31: «Haec enim duo quadam inter se communione confusa, coniecta differentia secernuntur, per quam quid sit utrumque cognoscitur; ut cum quaeritur quid inter regem sit et tyrannum, adiecta differentia, quid uterque sit definitur, ut "rex modestus et temperatus, tyrannus uero crudelis"»). 
Dictionnaire des antiquités (s.v., p.810-811.), originalmente Caesar es un cognomen $^{7}$ de la gens Iulia (1-3). Octavio, hijo adoptivo de Julio César, lo añadió a su nombre propio cuya terminación modificó (4) y como tal permaneció hasta la extinción de la familia Julia (5-6):

1) Cleopatra vero Alexandrinorum regina ... prius contra uiri sui Ptholomei insidias Gaium Iulium Caesarem interpellavit (Iord., Rom. 250).

2) Post hos imperator primus Iulius Caesar fuit, qui tutius imperii obtenuit monarchiam; secundus Octauianus, Iulii Caesaris nepus, quem Augustum uocant (Greg. 1.18).

3) Caesar uero, qui sibi primus omnium Romanum uindicauit imperium (Iord., Get. $11.68)^{8}$.

En los pasajes (2) y (3) se pone de manifiesto que Gregorio y Jordanes, en la línea de historiadores anteriores como Suetonio, consideran que el régimen imperial arranca en Roma con Julio César.

4) sic quoque Augustus Caesar Octauianus, quo nullus imperatorum in bellis felicior nec pace moderatior fuit (Iord., Rom. 255) ${ }^{9}$.

5) Tiberius Augustus Caesar regnauit ${ }^{10}$ ann. XXIII. qui multos reges ad se blanditiis euocatos numquam ad propria regna remisit, in quibus et Archelaum Cappadocum rege (Iord., Rom. 258).

6) Gaius Caesar cognomento Caligula regnauit ann. III menses X. hic namque Memmium Regulum coegit, ut uxorem suam sibi loco filiae coniugem daret strumentaque matrimonii ut pater conscriberet. (Iord., Rom.259).

Como también señalan el ThLL (Nomina propria latina, Supplementum I, col. 37-38), el Dictionnaire des antiquités (s.v., p.811) o el Lexicon des Mittelalters (s.v. 'Caesar' vol. II, col. 1352) ${ }^{11}$, a partir de Adriano, caesar ${ }^{12}$ puede denominar además al sucesor designado ${ }^{13}$ :

7 Para la indistinción entre praenomen y cognomen cf. Syme 1958, especialmente pp. 176 y 182

8 Cf. también Iord., Rom. 225; 240; Get. 2.10, etc.

9 Cf. también Iord., Rom. 112 y 252.

10 También sería interesante realizar el estudio de los verbos que expresan la idea de "reinar", "regir" y de los sustantivos abstractos relacionados con este concepto como regnum, imperium, etc., que dejaremos para otra ocasión.

11 Cf. también Barnwell 1992, p. 13, y Jones 1973, I, p. 322 ss.

12 Hemos optado por escribir caesar y augustus con minúscula cuando no son nombre propio, pero en los pasajes aducidos respetamos la grafía de los editores.

13 Con anterioridad sucede esto mismo, por ejemplo, en Lact., Mort. 25.5 «Constantinum uero non imperatorem, sicut erat factus, sed Caesarem cum Maximino appellari iuberet, ut eum de secundo loco reiceret in quartum»; Aur. Vict. 22.1 «Dehinc Opilius Macrinus, qui 
7) Tiberium caesarem sibi adsciuit ad defensandas prouintias suas (Greg. 4.40) ${ }^{14}$.

8) ob quae Constantius et Galerius Maximianus Caesares adsumuntur in regno.. (Iord., Rom. 298).

9) Stilico ... Eucherium filium suum paganum et Christianis insidias molientem cupiens Caesarem ordinare (Iord., Rom. 322).

10) Constantinus quidam apud Gallias inuadens imperium filium suum Constantem ex monacho fecerat Caesarem (Iord., Get. 32.165) ${ }^{15}$.

11) Nepotem filium Nepotiani copulata nepte sua in matrimonio apud Rauennam per Domitianum clientem suum Caesarem ordinauit (Iord., Rom. 338).

12) quod Basiliscus cognoscens Zenonisque fugam laetatus Marcum filium suum Caesarem ordinauit (Iord., Rom. 342) ${ }^{16}$.

13) Aspar ... cum Ardabure et Patriciolo filiis, illo quidem olim patricio, hoc autem Caesare generoque Leonis principis appellato, spadonum ensibus in palatio uulneratus interiit (Iord., Get. 45.239) ${ }^{17}$.

Diocleciano dividió el Imperio en dos partes dirigidas por dos augusti, él mismo y Maximino Herculio, y nombró a dos caesares, Constancio y Galerio (cf. Jones, p. 322 ss., Teja 1982, p. 77 n. 47). Cada augustus debía renunciar al poder a los 20 años para cederlo al caesar, quien ocuparía el cargo de augustus y nombraría un nuevo caesar. A estos caesares se refiere Jordanes en los siguientes pasajes:

14) ob quae Constantius et Galerius Maximianus Caesares adsumuntur in regno (Iord., Rom. 298) ${ }^{18}$.

15) sed et Carporum trea milia (...) quos tamen post haec imperante Dioclitiano et

praefecturam praetorio gerebat, imperator eiusdemque filius Diadumenus nomine Caesar a legionibus appellantur». Cf. al respecto ThLL (Nomina propria latina, Supplementum I, col. 37-38), Barnwell 1992, p. 13, y Jones 1973, I, p. 322 ss.

14 Tiberio fue elegido césar en el año 574, cf. Greg. 5.19. Cuatro años más tarde, en el año 578, fue nombrado emperador y como tal reinó hasta el 582 con el nombre de Tiberio II Constantino, cf. Greg. 5.30. Concretamente este pasaje se refiere al año 574, cf. Oldoni (2001: 277 n.119). En casos como éste, para determinar si en un momento determinado el término caesar presenta la acepción de 'emperador' o la de 'sucesor designado' se hace imprescindible recurrir a otros testimonios o a los manuales de historia.

15 Cf. Orosio 7.40.4. Por otro lado, en este pasaje se ve el origen del prefijo ex, que tiene aspecto resultativo en oposición a in-, para indicar que se ha dejado de ocupar un cargo o desempeñar un oficio.

16 Marco, hijo de Basilisco y Zenona fue proclamado caesar en 475 y más tarde nombrado augustus.

17 Cf. también Iord., Rom. 274; 324; 336; Get.16.91; etc.

18 Cf. Orosio 7.25.5: «Hoc periculo Diocletianus permotus Maximianum Herculium ex Caesare fecit augustum, Constantium uero et Maximianum Galerium Caesares legit». 
Maximiano Galerius Maximinus Caesar deuicit et rei publicae Romanae subegit. (Iord., Get. 16.91).

Finalmente en Jordanes y Gregorio caesar puede designar genéricamente al emperador, acepción que encontramos, aunque con poca frecuencia en historiadores anteriores como Tácito (Ann. I 5.2), Suetonio (Tit. 8.1) o Aurelio Víctor (41.10). El ThLL en el apartado IV de Caesar (Nomina propria latina, Supplementum I, col. 36-37) no distingue el uso de caesar como soberano del Imperio Romano y su uso como nombre propio o título de todos los emperadores, a excepción de Vitelio ${ }^{19}$. Ejemplos de este tipo son:

16) Valentinianum puerolum (...) a consubrino Theodosio imperatorem fuisse creatum et apud urbem Romam tyrannum Iohannem in imperium surrexisse, legatusque eius a caesare dicat fuisse dispectus ... (Greg. 2.8) ${ }^{20}$.

17) cuius nutu mox loco Valentiniani apud Rauennam Maiorianus Caesar est ordinatus, qui tertio necdum anno expleto in regno apud Dertonam occiditur (Iord., Rom. $335-336)^{21}$.

18) sed postquam Caesar Maximinus pene cum eorum solacia Narseum regem Persarum Saporis magni nepotem fugasset eiusque omnes opes simulque uxores et filios depraedasset Achillemque in Alexandria Dioclitianus superasset et Maximianus Herculius in Africa Quinquegentianos adtriuisset, pacem rei publicae nancti coeperunt quasi Gothos neglegere (Iord., Get. 21.110) ${ }^{22}$.

19) et necdum Olybrio octauo mense in regno ingresso obeunte Glycerius apud Rauennam plus presumptione quam electione Caesar effectus (Iord., Get. 45.239) ${ }^{23}$.

20) Pylatus autem gesta ad Tiberium caesarem mittit et ei tam de uirtutibus Christi quam de passione uel resurrectione eius insinuat (Greg. 1.24) ${ }^{24}$.

19 Cf. también Lexicon des Mittelalters, s.v. 'Caesar' col. 1353 y s.v. 'Kaiser' col. 852.

20 En este caso no hay duda porque es una uariatio de imperator.

21 Que Maiorianus es emperador lo avalan Sidonio Apolinar Carm. V. 511-552; La Chronica de Hidacio 200, p. 31 o la Chronica Caesaraugustana s.a. 460, p.222. Cf. Barnwell (1992, capítulo 2).

22 A pesar de que Maximino fue nombrado caesar por Diocleciano en 285 y augustus en 286 y de que lo que relata este pasaje sucede después del 293 (fecha en que fueron nombrados los dos césares, Constancio Cloro y Galerio), cuando ya era coemperador, el autor ha decidido darle el nombre de caesar. Sin embargo, Orosio hablando justo de esto mismo en 7,25,8 dice At Maximianus Augustus Quinquegentianos in Africa domuit, llamando a Maximino, por tanto, augustus.

23 Que este personaje es emperador lo sabemos por otros pasajes de esta misma obra: «qui accito germano missaque sorte hortatus est, ut ille in parte Italiae, ubi tunc Glycerius regnabat imperator, ipse vero sicut fortior ad fortiorem regnum accederet Orientalem: quod et factum est» (Iord., Get. 56.283), cf. también Get. 44.241 y 56.284 .

24 Cf. «ut Gesta Pilati ad Tiberium imperatorem missa referunt» (Greg. 1.21). 
21) adiecit: Nihil Arbogastis differre uolens, conmonet caesarem poenas debetas a Francis exigendas, nisi universa, quae superiore anno caesis legionibus diripuerant, confestim restituerent (Greg. 2. 9) ${ }^{25}$.

Quizá esta acumulación de acepciones en caesar, con la ambigüedad a la que puede dar lugar en algunos pasajes, hace que este nombre sea relativamente poco utilizado para referirse al emperador, frente a otros términos que vamos a ver a continuación; aunque en español césar (cf. $D R A E$, s.v.) y en italiano cesare siguen conservando esta acepción.

\subsection{Augustus}

En el ThLL (s.v., II, cols. 1381-1384), el Lexicon des Mittelalters (s.v., vol. I, col. 1231) y el Dictionnaire des antiquités (s.v. I 561) se lee que Augustus es, en primer lugar, el cognomen del emperador Octaviano Augusto:

22) necessarium est ergo nobis ea interim, que ad tempora Augusti imperatoris dicuntur, omittere (Iord., Rom. 86).

23) a meridie item ipse Padus, quem Italiae soli fluuiorum regem dicunt, cognomento Eridanus, ab Augusto imperatore latissima fossa demissus (Iord., Get. 29.150) ${ }^{26}$.

A partir de este cognomen, augustus se convierte en un título honorífico que acompaña al nombre de los emperadores, como se apunta en el ThLL (s.v., II, cols. 1384-1388), en el Lexicon des Mittelalters (s.v. vol. I, col. 1232) y en el Dictionnaire des antiquités (s.v. I 561):

24) Augustus imperator, qui et Octauianus dicebatur, a quo posteri principes Augusti sunt uocati, tam ciues patrios rebellans quam etiam gentes exteras superans, singularem sibi uindicat principatum, regnans per ann. LVI (Iord., Rom. 85).

25 ) ipse singularem optenuit principatum et posteris eandem imperii potestatem cum suo nomine Augusti derelinquens rebus excessit humanis, successorem relinquens Tiberium preuignum suum ${ }^{27}$ (Iord., Rom. 257).

26) sic quoque Hesperium Romanae gentis imperium, quod septingentesimo nono urbis conditae anno primus Augustorum Octauianus Augustus tenere coepit, cum hoc Augustulo periit anno decessorum prodecessorumue regni quingentesimo uicesimo secundo, Gothorum dehinc regibus Romam Italiamque tenentibus (Iord., Get. 46.242-243).

Incluso, según Gregorio, este título se le puede otorgar a un rey (cf. Oldoni 2001: 149 n. 155):

\footnotetext{
25 Se trata de Valentiniano II. Para otros pasajes similares, cf. Iord., Rom. 358 o Get.

26 Cf. Greg. 1.18 (supra); 1.25; Iord., Rom. 2; 4; 84; 252 y Get. 47.245.

27 Cf. supra Tiberius Augustus Caesar (Iord., Rom 258).
} 15.86 . 
27) Chlodouechus (...) igitur ab Anastasio imperatore codecillos de consolato accepit ... et ab ea die tamquam consul aut augustus est uocitatus (Greg. 2.38).

Durante la tetrarquía se dio el nombre de augustus al sucesor designado que ayudaba al emperador en las tareas de gobierno y que tenía por debajo a los dos caesares (cf. 7-13). No hemos encontrado ejemplos de este uso ni en Jordanes ni en Gregorio. Pronto pasa a designar el cargo mismo de gobernante supremo de Roma, el 'emperador', acepción que no está nada clara en el ThLL ni en los historiadores anteriores a los aquí estudiados. Así ocurre en los siguientes pasajes:

28) Theodosius Spanus, Italicae diui Traiani ciuitatis a Gratiano Augusto apud Sirmium post Valentis interitum factus est imperator regnauitque an. XVII (Iord., Rom. $315)^{28}$.

29) Halaricus rex Vesegotharum vastatam Italiam Romam ingressus est opesque Honorii Augusti depraedatas Placidiam sororem eius duxit captiuam. (Iord., Rom. 323) ${ }^{29}$. 30) post cuius (sc. Claudii) mortem Quintilius frater eius a senatu Augustus appellatus octauo decimo imperii sui diae Aquilaeia occisus est. (Iord., Rom. 289).

31) Verina Augusta ... fratrem suum Basiliscum in imperio inducens Augustum in urbe appellauit (Iord., Rom. 341).

32) Theodoricus uero Zenonis Augusti humanitate pellectus Constantinopolim uenit, ubi magister militum praesentis effectus consulis ordinarii triumphum ex publico dono peregit (Iord., Rom. 348).

33) Ipse postmodum augustus dum in campo Martio pro tribunali resedens concionaretur ad populum, Occila, buccellarius Aeti, ex aduerso ueniens, eum gladio perfodit (Greg. 2.8).

34) Aureus etiam singularum librarum pondere, quos imperatur misit, ostendit, habentes ab una parte iconicam imperatoris pictam et scriptum in circulo: TIBERII CONSTANTINI PERPETVI AVGVSTI; ab alia uero parte habentes quadrigam et ascensorem contenentesque scriptum: GLORIA ROMANORVM. (Greg. 6.2).

35) Illus autem Isaurus, magister officiorum et Zenoni imperatori in priuata uita ami-

28 Esta es la única ocasión en que Graciano es llamado augustus tanto en Jordanes como en Gregorio. En otras ocasiones le denominan imperator (Cf. Iord., Rom. 312; Get. 27.139 hablando exactamente del mismo hecho histórico -; 141; 142 y 145 y Greg. 1.41; 42 y 43). Aquí, sin duda, es emperador pues, tras la muerte de Valente y viéndose solo en el mando, decide nombrar como colega en el imperio a Teodosio (cf. Oros. 7.34.2; Aur. Vict. 48.1).

29 Cf. también Get.31.160. En otros pasajes se denomina a Honorio imperator: «Hesperia uero plaga in regno Honorii imperatoris primum Radagaisus Scytha cum ducenta milia suorum inundauit» (Iord., Rom. 321); cf. también Iord., Get. 30.152 y 30.154, o princeps: «Stilico uero comis, cuius duae filiae Maria et Hermantia singulae uxores Honorii principis fuere et utraeque uirgines sunt defunctae ... gentes donis pecuniisque inlectas contra regnum Honorii excitaui» (Iord., Rom. 322). 
cissimus caritateque coniunctus, dum secreto in detractionem Ariagnes Augustae cum eius uiro locutus est, in zelo Augustum concitauit (Iord., Rom. 349) ${ }^{30}$.

En augustus no hay tanta acumulación de acepciones como en caesar, pero tampoco se utiliza con mucha frecuencia para designar al emperador romano. De hecho, en español y otras lenguas románicas modernas ya no conserva este significado.

\subsection{Augusta}

Augusta es título que suele acompañar al nombre de la emperatriz regente y así lo recogen el ThLL II, (s.v. Augustus, col. 1389-1390), y el Dictionnaire des antiquités (s.v. I 561) ${ }^{31}$ :

36) Theodora Augusta euocatur ad urbem Belesarius de Siciliam (Iord., Rom. 382).

37) Honoriam Valentiniani principis germanam, filiam Placidiae Augustae (Iord., Get. 42.223).

38) Dominica Augusta Valentis uxor multa pecunia plebi largita ab urbis uastatione hostes submouit regnumque cognatis, usque dum ille Theodosium ordinasset, fideliter uiriliterque seruauit (Iord., Rom. 314) ${ }^{32}$.

\subsection{Imperator}

Imperator en latín clásico designaba al general o jefe de un ejército (ThLL VII, s.v. II, cols. 554-556; Dictionnaire des antiquités grecques et romaines, s.v. p.431-434). En Jordanes encontramos algunos ejemplos de este uso:

39) tum Scipione duce fusus exercitus: saucius etiam ipse uenisset in hostium manus imperator, nisi protectum patrem praetextatus ammodum filius ab ipsa morte rapuisset (Iord., Rom. 185).

40) Tharsymenus lacus tertium fulmen Annibalis imperatore Flamminio (Iord., Rom. $187)^{33}$.

Como podemos leer en Suetonio (Iul. 76,1), el Senado concedió en el año 45 a. C. el praenomen de imperator a Julio César y Octaviano se encargó de convertirlo en un título, relacionado con la posesión del imperium (Syme

30 La sinonimia de augustus e imperator (cf. infra) se ve bien en el siguiente pasaje de Isidoro: «Mortuo Iulio Cesare Octauianus nepos eius Romanum suscepit imperium et dictus est Augustus, id est imperator» (Isid., Exord. 24).

31 Cf. también Jones 1973, p. 341.

32 Cf. también Iord., Rom. 274; 327; 337; 342; 351; Greg. 5.19; etc.

33 Cf. también Iord., Rom. 165; 168 y 188. 
1958, pp. 176 y 182). Poco a poco se convierte en uno de los vocablos más frecuentes, junto con princeps como veremos después, para designar a la figura misma del gobernante máximo (Cf. ThLL VII, s.v. III, col. 556 ss.), quizá por ser menos ambiguo que caesar y augustus y por estar relacionado etimológicamente con imperium e imperare. Este nuevo sentido ya se documenta desde Tácito (Ann.XI 11; Hist. II 8. 80). Para los pasajes que hacen referencia a Julio César y Augusto como imperatores cf. supra en 2.2. y 2.3. También se llama imperator a Aureliano (Iord., Rom. 217), Claudio (Iord., Rom. 225, Greg. 1.25), Macrino (Iord., Rom. 278) Probo (Iord., Rom 293); Valentiniano (Iord., Rom. 311) ${ }^{34}$, Graciano (Iord., Rom. 309, 312, Greg. 1.42) $)^{35}$, Teodosio (Iord., Rom. 319) ${ }^{36}$, Trajano (Iord., Get. 16.93), Decio (Iord., Get. 18.102), Maximiano (Iord., Get. 21.110), Valente y Valentiniano (Iord., Get. 25.131), Honorio (Iord., Get. 30.152) ${ }^{37}$, León (Iord., Get. 45.236) ${ }^{38}$, Glicerio (Iord., Get. 45.241, 56.283, 56.284) ${ }^{39}$, Augústulo (Iord., Get. 46.242), Tiberio (Greg. 1.21) ${ }^{40}$, Máximo (Greg. 1.43), Secundino (Greg. 3.33) y Mauricio (Greg. 10.1). Para otros pasajes en que se habla de manera genérica del emperador o los emperadores, cf. por ejemplo:

41) Traianus pene omnium imperatorum potior regnauit an. XVIII m. VI. (Iord., Rom. 267).

42) hic etenim filium suum idem Philippum consortem regni fecit ipseque primus omnium imperatorum Christianus effectus est (Iord., Rom. 283).

43) Gothi uero occiso imperatore iam securi ad urbem properant Constantinopolitanam (Iord., Rom. 314).

44) 'deus', inquit, 'sine dubio terrenus est imperator et quisquis aduersus eum manu mouerit, ipse sui sanguinis reus existit' (Iord., Get. 28.143).

45) Postquam ergo firma pax Gothorum cum Romanis effecta est, uidentes Gothi non sibi sufficere ea quae ab imperatore acciperent ... coeperunt uicinas gentes circumcirca praedari (Iord., Get. 53.272).

Como ocurre en otros autores (cf. ThLL VII 560, 5-19), Gregorio de forma excepcional emplea imperator para referirse al soberano persa, normal-

34 A quien se llama princeps en Iord. Get. 33.167, 36.185 y 42.223 y en Greg. 2,9 y augustus en Greg. 2,9.

35 Augustus en Iord., Rom. 315, como ya dijimos antes.

36 Princeps en Iord., Rom. 328 y 329.

37 Augustus en Iord., Rom. 323 y Get. 31.160 y princeps en Rom. 322.

38 Princeps en Iord., Get. 45.239 y 52.271.

39 Caesar en Iord., Get. 45.239.

40 Caesar en Greg. 1.24. 
mente designado como rex (Fanning 1991):

46) Ad Iustinum autem imperatorem Persi-Armeni (...) uenerunt, petentes amicitias eius atque narrantis, se imperatori Persarum esse infensus (Greg. 4.40).

Imperator se revela como el término que estos autores encuentran más apropiado para referirse al jefe del Imperio Romano y es, por tanto, uno de los que más se utiliza. En español no solo designa al jefe supremo del antiguo Imperio Romano, sino que también es el título de mayor dignidad dado a ciertos soberanos (cf. DRAE, s.v.), como ocurre también en francés con empereur, en italiano con imperatore, en inglés con emperor, etc.

\subsection{Princeps}

Princeps en Jordanes y Gregorio puede tener los mismos sentidos que tenía en latín clásico donde designaba a los primeros y, a partir de aquí, a los que ocupaban los puestos más destacados, que pasan a ser la clase dominante (Cf. THLL X, s.v. III, col. 1279 ss.; Dictionnaire des antiquités, s.v. pp. 648-657 y Lexicon des Mittelalters, s.v. Princeps y Fürst, vols. VII y IV):

47) at uero ubi milites principe meliore mutato fiduciam acceperunt, Gothos impetere temptant (Iord., Get.27.140).

48) arbitratur se mundi totius principem constitutum et per Martis gladium potestatem sibi concessam esse bellorum (Iord., Get. 35.183).

49) Valentinianus et Novatianus maxime tunc heretiquorum principes contra fidem nostram ... crassantur (Greg. 1.30).

50) Ioseph ... ab ipsis sacerdotum principibus custoditur (Greg. 1.21).

51) hic directo Scopa principe militiae capit Iudaeam (Iord., Rom. 77).

52) itaque mirum in modum exercita iuventute provocare ausus Albanos grauem et diu principem populum (Iord., Rom. 96) ${ }^{41}$.

Al principio de la época imperial, para indicar claramente que no es más que el primus inter pares, el emperador toma oficialmente el título de princeps (cf. supra 24). En nuestros autores es uno de los términos más frecuentes para designar al Jefe del Imperio Romano, acepción que, documentada ya en Ovidio, es frecuente en los historiadores a partir de Tácito (cf. ThLL s.v. X 2, col.1283, 54). Así se donomina a los siguientes emperadores, que en otros pasajes son designados a veces como caesar, augustus o imperator (cf. supra, ejemplos 16-21; 28-35 y apartado 2.4): Augusto (Iord., Rom. 254), Teodosio (Iord., Rom. 328; Get. 27.139; 27.140; 28.144), Constantino (Iord., Get. 28.145; Greg. 2.9) Antemio (Iord., Get. 45.236; 45.238), León

${ }^{41}$ Cf. además Iord., Rom. 105; 180; Greg. 5.5; 7.36; 9.10; 10.16, etc. 
(Iord., Rom. 336; Get. 45.239; 45.240; 52.271), Arcadio (Iord., Rom. 319), Justiniano (Iord., Rom. 368), Honorio (Iord., Rom. 322; Get. 32.165), Valentiniano (Iord., Get. 33.167; 36.185; 42.223, Greg. 2.9). Otros pasajes en que equivale a imperator son, por ejemplo:

53) Langobardorum gens, socia Romani regni principibus (Iord., Rom. 386).

54) nam Vandali vel Alani, quos superius diximus permissu principum Romanorum utramque Pannoniam resedere ... ad Gallias transierunt (Iord., Get. 30.161).

55) eisque in mandatis ac si testamentali uoce denuntians, ut regem colerent, senatum populumque Romanum amarent principemque Orientalem placatum semper propitiumque haberent post deum (Iord., Get. 59.304).

56) inter haec ergo Theodoricus Zenonis imperio foedere sociatus ... secumque deliberans ad principem ait: "quamuis nihil deest nobis imperio uestro famulantibus, tamen, si dignum ducit pietas uestra, desiderium mei cordis libenter exaudiat" (Iord., Get. 57.290).

Junto con imperator, princeps es uno de los términos más utilizados para referirse al emperador, quizá porque nunca formó parte del nombre propio y su sentido etimológico resulta siempre transparente. Aunque también, como veremos más adelante (cf. 3.7), designa a otros tipo de soberanos.

\section{Otros gobernantes}

\subsection{Rex}

El término se empleó en latín para designar a los reyes romanos anteriores a la República:

57) breuiter referam: uel etiam quomodo regum series a Romulo et deinceps ab Augusto Octauiano in Augustum uenerit Iustinianum, quamuis simpliciter, meo tamen tibi eloquio pandam. (Iord., Rom.2).

58) necessarium est ergo nobis (...) originemque Romuli eius conditoris exponere simulque successorum eius regum consolumque annos actosque ad liquidum demonstrare, qui sunt hi (Iord., Rom. 86).

59) Ab origine urbis Romae et usque Tarquinium regem cognomento Superbum, qui et expulsus est, numerantur anni CCXLIII (Iord., Rom. 87).

60) Postremus fuit omnium regum Tarquinius, cui cognomen Superbo ex moribus datum (Iord., Rom.103).

61) Haec est prima aetas populi Romani et quasi infantia, quam habuit sub regibus septem, per annos, ut diximus, CCXLIII, quadam fatorum industria tam uariis ingenio, ut rei publicae ratio et utilitas postulabat (Iord., Rom.108) ${ }^{42}$.

42 Cf. además Iord., Rom. 4; 91; 93; 97; 99; 107, etc. 
En general, como sucede en historiadores anteriores (cf. César, Salustio, Livio, Tácito, Suetonio, etc.), el que ostenta el poder en otros pueblos o naciones, desde el origen del mundo, es el rex. Así Jordanes menciona al rex o a los reges Assyriorum (Iord., Rom.13), Hebreorum (Iord., Rom. 42; 83), Medorum (Iord., Rom. 50; 57; Get. 6.47), Iudeorum (Iord.,, Rom. 55), Babyloniorum (Iord., Rom.57), Graecorum (Iord., Rom.71), Syriae (Iord., Rom. 76; 227), Etruscorum (Iord., Rom. 120), Epyrotarum (Iord., Rom. 150), Pergamenorum (Iord., Rom. 208), Macedonum (Iord., Rom. 209; Get. 10.66), Pannonum (Iord., Rom. 216), Dacum (Iord., Rom. 217), Cappadocum (Iord., Rom. 224; 225), Paflagoniae (Iord., Rom. 226), Armeniae (Iord., Rom. 232; 234); Aegyptiorum (Iord., Get. 6.47); Parthorum (Iord., Get. 20.108), Persarum (Iord., Rom. 57; 280; 287; 297; 302; Get. 10. 61; 10. 63) ${ }^{43}$, Vesegothorum (Iord., Rom. 223; 326; Get. 5.30), Hunnorum (Rom. 328; 331); Vandalorum (Iord., Rom. 330; 331; 334; 337), Gothorum (Iord., Rom. 321; 346; 347; Get. 6.48; 16.90; Greg. 2.4), Francorum (Greg. 2.9.) ${ }^{44}$, Getarum (Iord., Rom. 336); Italiae (Iord., Rom. 367); o en particular se refiere con este título a Darío (Iord., 10. 63), Herodes (Greg. 1.24), Halarico (Iord., Rom. 319; 323), Teodorico (Iord., Get. 5.24), Gunderico (Greg. 2.2) etc.

Este vocablo se ha perpetuado en las lenguas modernas, cf. español rey (DRAE, s.v.), en francés roi, en italiano re, etc.

\subsection{Regina}

Con este nombre se designó en latín clásico a las mujeres de los reyes romanos anteriores a la República, a Cleopatra y a otras reinas de la mitología. Todos estos usos perduran en Jordanes:

62) ergo inter Tarquinii mortem annitente regina substitutus in locum regis quasi in tempus regnum dolo partum sic egit industriae, ut iure adeptus uderetur (Iord., Rom.101).

1) Cleopatra uero Alexandrinorum regina ex genere Lagidarum Ptholomeorumque successor prius contra uiri sui Ptholomei insidias Gaium Iulium Caesarem interpe-

43 Sin embargo, como ya dijimos más arriba, Gregorio en una ocasión (4.40) se refiere a los mismos como imperatori Persarum.

44 Sobre el problema del Fracorum rex, cf. Oldoni 2001, p. XLVIII y ss.. Es importante reseñar el pasaje en que Gregorio habla sobre el inicio de la monarquía de los francos: «De Francorum vero regibus, quis fuerit primus, a multis ignoratur. Nam cum multa de eis Sulpici Alexandri narret historia, non tamen regem perimum eorum ullatinus nominat, sed duces eos habuisse dicit» (Greg. 2.9). 
llauit, (Rom. 250). Cf. supra

63) hae quoque Amazones post haec habuere reginam nomine Penthesileam (Iord., Get. 8.57).

Este es también el término con que se designa a las esposas de los reyes de otros desde los comienzos de la historia, como ocurre en español con rei$n a(D R A E$, s.v.), en francés con reine, en italiano con regina, etc.:

64) Tunc Cyrus, rex Persarum, post grande interuallum et pene post DCXXX annorum tempore (Pompeio Trogo testante) Getarum reginae Thomyre sibi exitiabile intulit bellum (Iord., Get. 10.61).

65) Igitur ex Chrotchilde regina habuit filium primogenitum (Greg. 2.29).

66) Igitur interempto Sigybertho rege apud Victuriacum uillam, Brunichildis regina cum filiis Parisius resedebat. (Greg. 5.1).

\subsection{Regnator}

Además de rex, estos autores utilizan otros términos para designar a los dirigentes de otros pueblos. Uno de ellos es regnator. Este término, documentado ya en Nevio, Accio o Plauto, es muy poco frecuente en la literatura latina en general y sólo se encuentra una vez el historiador Tácito (Germ. $39.2)^{45}$, pero su empleo aumenta en los autores cristianos (Tertuliano, Arnobio, Paulino de Nola, Agustín, Casiodoro - autor que le sirve de fuente ${ }^{46}$ etc.). Jordanes lo utiliza en alguna ocasión como equivalente a rex:

67) Attila, Hunnorum omnium dominus et paene totius Scythiae gentium solus in mundo regnator (Iord., Get. 34.178).

68) suaeque gentis uestitum seponens insigne regio amictu, quasi iam Gothorum Romanorumque regnator, adsumit (Iord., Get. 57.295).

Gregorio no lo emplea en la Historia Gothorum, pero sí en De miraculis Beati Andreae sólo para referirse a Dios ${ }^{47}$.

\subsection{Regulus}

El término regulus, que en Salustio y Livio designaba al hijo de rey o al rey niño, en Livio y Tácito también se refiere al rey de un pequeño estado ${ }^{48}$

45 En Tácito también encontramos el único ejemplo del adjetivo regnatrix (Ann. I 4.4).

46 Cf: «aes enim Ionos Thessaliae rex, plumbum Mida regnator Phrygiae reppererunt» (Cassiod. Var. 3.31).

47 «Regnator caelorum et terrae, qui est filius omnipotentis Dei, cum Spiritu sancto verus Deus, permanens in saecula sempiterna »(Greg., De miraculis Beati Andreae 20).

48 Cf. «Micipsa paucis post diebus moritur. postquam illi more regio iusta magnifice 
con un claro sentido despectivo. Lo mismo ocurre en historiadores tardíos y en autores cristianos como Floro, Amiano Marcelino, Historia Augusta, Pseudo Aurelio Víctor, Orosio, Tertuliano, Ambrosio, Agustín, Jerónimo y en la Biblia, fuentes más cercanas de Jordanes:

69) Lupicinus ut ductor Romanorum Fritigernum Gothorum regulum in conuiuio inuitaret (Iord., Get.26.135-6).

70) nam perpendens Attila sagacitate sua, eum et Valamerem, Ostrogotharum regem, super ceteros regulos diligebat (Iord., Get.38.199).

71) Rimismundum sibi Suaui regulum ordinauerunt (Iord., Get.44.234).

\subsection{Subregulus}

Término tardío, que se encuentra documentado en historiadores desde el siglo IV (Sulpicio Severo, Amiano Marcelino y Jerónimo) y en la Biblia para referirse a un reyezuelo o vasallo. En Gregorio se aplica a un personaje, Marcomere, a quien también se denomina dux y Francorum regalis (cf. infra 3.7) ${ }^{49}$ :

72) Eodem anno Arbogastis Sunnonem et Marcomere subregolus Francorum gentilibus odiis insectans, Agrepinam regentem maxime hieme petiit (Greg. 2.9).

\subsection{Regalis}

Es también un término tardío con el que Amiano designa a los hijos de reyes ${ }^{50} \mathrm{y}$, sin embargo, en Gregorio tiene el mismo valor que subregulus:

fecerant, reguli in unum convenerunt» (Sall. Iug. 11.2); «regulus cum tutore et exigua Masaesuliorum manu in Carthaginiensem agrum perfugit» (Liu. XXIX 30.10); «inter Q. Sulpicium tribunum mili tum et Brennum regulum Gallorum conloquio transacta res est» (Liu. V 48.8). «At ex regulis prior Mithridates Pharasmanen perpulit dolo et ui conatus suos iuuare (Tac., Ann. VI 33.1).

49 El propio Gregorio hace una reflexión sobre la denominación de este personaje en su fuente, Sulpicio Alejandro (Cf. Oldoni 2001: 97-99, nota 49).

50 «quorum regalis Vitrodorus, Viduari filius regis, et Agilimundus subregulus alii que optimates et iudices uariis populis praesidentes uiso exercitu in gremio regni soli que genitalis sub gressibus iacuere militum et adepti ueniam iussa fecerunt subolem que suam obsidatus pignore ut obsecuturi condicionibus impositis tradiderunt eductis que mucronibus, quos pro numinibus colunt, iurauere se permansuros in fide» (Amm. XVII 12.21); «dum haec celerantur, Hortarius rex nobis antea foederatus non nouaturus quaedam, sed amicus finitimis quoque suis reges omnes et regales et regulos ad conuiuium corrogatos retinuit epulis ad usque uigiliam tertiam gentili more extentis; quos discedentes inde casu nostri ex improuiso adorti nec interficere nec corripere ullo genere potuerunt tenebrarum equorum que adiumento, quo dubius impetus trusit, abreptos» (Amm. XVIII 2.13. 13); cf. también Amm. XVI 10. 16; 12. 26; 
73) Haec acta, cum duces essent, retulit; et deinceps ait: Post dies paucolus, Marcomere et Sunnone Francorum regalibus transacto cursim conloquio imperatisque ex more obsidibus, ad hiemandum Treuerus concessit (Greg. 2.9).

74) Cum autem eos regales uocet, nescimus, utrum reges fuerint, an in uices tenuerunt regnum (Greg. 2.9).

75) Iterum hic, relictis tam ducibus quam regalibus, aperte Francos regem habere designat, huiusque nomen praetermissum (Greg. 2.9).

\subsection{Princeps}

En Jordanes, y más frecuentemente en Gregorio, princeps presenta una acepción bastante tardía para denominar a los reyes de otros pueblos (cf. ThLL, s.v. X 2, col. 1283, 4), alternando en esta acepción con rex ${ }^{51}$ :

76) rex sum ego, sicut et ille". Et egressus coepit seducere populum, dicens: "Princeps ego sum" (Greg. 3.14).

77) His diebus Austrigildis Guntchramni principis regina ab hoc morbo consumpta est (Greg. 5.35) ${ }^{52}$.

78) stetit sub praetio Marcomannus, Quadorum principes in seruitute redacti sunt (Iord., Get. 16.89) ${ }^{53}$.

79) quos ille pontificali reuerentia suscipiens non solum inpunitatem Suauorum indulsit, sed ut sibi de suo genere principem constituerent, flexus pietate concessit (Iord., Get. 44.234) ${ }^{54}$.

En el siguiente pasaje queda patente que a veces princeps es una simple uariatio de rex:

80) Tollantur a faciae regis, qui regnum eius uenundant, ciuitates illius dominatione alteri subdunt, populus ipsius principis alterius dicionibus tradunt' (Greg. 6.31) ${ }^{55}$.

También princeps puede hacer referencia al mismo tiempo a imperator $\mathrm{y}$

12. 34; XVII 12.10; XXIV 2.11; XXVI 8. 12 ; XXVII 10. 101.

${ }^{51}$ En Gregorio, como en la Biblia y otros autores cristianos (cf. ThLL X 1288, 60 ss.), también se refiere al diablo: «Princeps uero noster, quem uos diabolum nominatis, nihil in ea participatur» (Greg. 6.29); «Et quia princeps tenebrarum mille habet artes nocendi, quid de reclausis ac Deo deuotis nuper gestum fuerit, pandam» (Greg. 8.34).

52 En Greg. 5.14 a este mismo personaje se le llama rex. Para más ejemplos de este tipo, cf. Greg. 7.21 o 10.16 .

53 Tácito (Ann. II 63.6) al hablar de Vanio se refiere a él como rey de los quados: «barbari utrumque comitati, ne quietas prouincias immixti turbarent, Danuuium ultra inter flumina Marum et Cusum locantur, dato rege Vannio gentis Quadorum».

54 Para más pasajes en los que con princeps se hace referencia a reyes, cf. Greg. 4.26, $4.39,5.25,5.27,5.32 ; 6,3 ; 7,13 ; 8,28 ; 9,42 ; 10,5$.

55 Para más ejemplos de este tipo, cf. Greg. $7.21 ; 10,16$. 
a rex como el término más genérico para designar al soberano:

81) pax inter regis nostros imperatoremque uestrum (...) Testem hodie inuoco Deum, quia uestra excitauit noxa, ut non custodiatur inter principes pax promissa (Greg.10.2) ${ }^{56}$.

82) eodemque anno post diuturnum immanemque laborem, quod contra Parthos Romanorum fuisset gestum sudoribus, per Rufinum patricium perque Hermogenem magistrum officiorum et utrumque legatum directum a principe pax depicta est foedusque initum et munera ab utroque sibi inuice principe distinata (Iord., Rom. 365).

Estos ejemplos nos permiten deducir que princeps es de todos los términos examinados el único que puede expresar el concepto general de soberano de un estado independientemente del pueblo al que gobierne, lo que también sucede actualmente en español con príncipe (cf. DRAE, s.V., acepción 4), en francés con prince, en italiano con principe o en inglés con prince.

\section{Conclusiones}

El vocabulario que designa al gobernante en estos autores presenta algunas novedadades léxicas respecto al empleado desde el inicio del régimen imperial en Roma y, sobre todo, innovaciones semánticas.

Para nombrar al emperador romano emplean caesar, augustus, imperator y princeps. En algunas ocasiones es difícil determinar si caesar se refiere al nombre propio o al título, al sucesor designado, al uso concreto que tiene en la tetrarquía o al término genérico para emperador. Cuando aparece augustus también hay dificultad para distinguir si se trata del título honorífico o de la designación genérica del emperador, a lo cual se añade el uso específico como co-emperador que tiene en la tetrarquía. Quizá por esa mayor ambigüedad caesar y augustus son menos frecuentes con esa acepción.

Sin embargo, imperator, que pasa de ser un cargo a ser praenomen con César y título con Augusto (de forma parecida a los dos vocablos anteriores), se convierte pronto en uno de los términos que prevalecen para designar al emperador, quizá por su relación etimológica con imperium e imperare. Princeps también es extraordinariamente frecuente con esta acepción, probablemente por no formar parte de ningún nombre propio, por su etimología transparente y por no presentar ambigüedad en su uso.

La existencia de cuatro términos para designar al emperador puede deberse a una primitiva vacilación sobre el nombre que había que dar a la figu-

56 En este caso el rey es Childeberto y el emperador Mauricio. 
ra que está al frente de la nueva forma de gobierno. Los cuatro son títulos que el emperador asume desde el primer momento. A medida que pasa el tiempo, caesar y augustus adquieren sentidos más específicos en detrimento de esta acepción. Sin embargo, imperator y princeps consolidan este sentido como el más importante.

A la hora de nombrar al soberano de otros pueblos el vocablo clásico rex sigue siendo el más usado (excepcionalmente aparece una vez en Gregorio una referencia al imperator Persarum, que normalmente es denominado rex). También es frecuente el empleo de princeps, con un sentido más general, para designar a cualquier soberano, lo que constituye una novedad del latín tardío. Para llamar a reyezuelos o reyes de pequeños estados, recurren a términos menos frecuentes en latín clásico como regnator o regulus, cuyo empleo aumenta en historiadores tardíos y en autores cristianos, e incluso a términos tardíos, documentados ampliamente en autores cristianos y la Biblia, como subregulus o en historiadores como regalis.

Para la consorte del emperador romano sólo se documenta el empleo de augusta, y regina para la consorte del soberano de otros pueblos. De modo que no hay ninguna variación respecto al latín clásico.

El uso de estos términos es muy semejante en ambos historiadores. La única diferencia que merece ser constatada es que para nombrar a los soberanos de otros pueblos con términos distintos a rex o princeps, Jordanes utiliza vocablos que ya estaban presentes desde antiguo en la lengua latina, como regnator o regulus, mientras Gregorio recurre a innovaciones tardías como subregulus y regalis.

Algunos de los términos estudiados terminaron desapareciendo con la propia lengua latina. Así sucede con los que designan al soberano de pequeños estados (regnator, regulus, subregulus y regalis). Otros se han conservado sólo para referirse a la época del Imperio Romano, como sucede con caesar (español césar e italiano cesare) y augustus (español augusto e italiano Augusto). Finalmente, una serie de vocablos continúan vigentes y productivos en las lenguas modernas en las que se siguen utilizando para designar al soberano de un estado de época antigua, pero también a monarcas de épocas más modernas e incluso actuales. Es el caso de imperator (español emperador, francés empereur, italiano imperatore, inglés emperor, etc), rex (español rey, francés roi, italiano re, etc.), regina (español reina, francés reine, italiano regina, etc.) y princeps (español príncipe, francés prince, italiano principe o inglés prince). 


\section{BIBLIOGRAFÍA}

\section{DICCIONARIOS Y ENCICLOPEDIAS}

Diccionario de la Lengua Española on line (DRAE), www.rae.es

Dictionnaire des antiquités grecques et romaines, 1877, Daremberg, Ch. et Edm. Saglio (dir.), París.

Dictionnaire latin-français des auteurs chrétiens, 1954, A. Blaise, revu specialment pour le vocabulaire theologique par H.Chirat, Turnhout: Brepols.

Dictionnaire latin-français des auteurs du Moyen Age: Lexicon Latinitatis Medii Aevi, 1986, A. Blaise, Turnhout.

Glossarium mediae et infimae latinitatis: Unveränderter Nachdruck der Ausgabe von 18831887, 1954, Ch. Du Cange, C. De Fresne, Graz.

Glossary of Later Latin to 600 a.D., 1949, comp. by A. Souter, Oxford.

Lexicon des Mittelalters (1977), edd. R. Berater - H. Bautier - R. Autg, Múnich, Zurich.

Thesaurus Linguae Latinae, 1900 ...., Leipzig, (ThLL).

\section{TEXTOS}

CD-Rom 2002, Library of Latin texts CLCLT-5, moderante Paul Tombeur.

CD-Rom 2002, Monumenta Germaniae Historica eMGH-3.

Lactancio, 1982, Sobre la muerte de los perseguidores, introducción, traducción y notas de R. Teja, Madrid.

Gregorio de Tours, 2001, Storia dei Franchi. I dieci Libri delle Storie, a cura di M. Oldoni, Nápoles.

\section{ESTUDIOS}

Barnwell, P. S., 1992, Emperor, Prefects and Kings. The Roman West, 395-565, Chapel HillLondres.

- 1997, Kings, Courtiers and Imperium. The Barbarian West, 565-725, Londres.

Bonnet, L., 1890, Le latin de Grégoire de Tours, Paris (reimpr. Hildesheim 1968).

Cameron, A., 1998, El mundo mediterráneo en la Antigüedad Tardía 395-600, trad. castellana de $\mathrm{M}^{\mathrm{a}}$ Eugenia Aubet, Barcelona, pp. 21-22

Conde Salazar, M. - Martín Puente, C. (en prensa a),«El vocabulario característico de la historiografía latina tardía. El ejemplo de Gregorio de Tours y Jordanes», RSEL, 34.I.

- (en prensa b) «La denominación de los gobernantes en la historiografía latina tardía. Estudio léxico».

Fanning, S., 1991, «Bede, Imperium, and the Bretwaldas», Speculum 66, pp.1-26

Hague, B. J., 1988, Cultures in collision: the barbarization of the Western Roman Empire in ideology and reality (c. 370 - 530 A. D.), Cambridge.

Jones, A. H. M., 1973, The Later Roman Empire 284-602, Oxford.

Kelly, Ch., 1998, «Emperors, Government and Bureaucracy», en A. Cameron-P. Garnsey (eds.), The Cambridge Ancient History. Volume XIII. The Late Empire, A.D. 337 - 425, Cambridge, pp.138-183.

Matthews, J., 2000, «The Roman Empire and the Proliferation of Elites», Arethusa 33, pp.429446. 
McCormick, M., 2000, «Emperor and Court», en A. Cameron, B. Ward-Perkins, M. Whitby (eds.), The Cambridge Ancient History. Volume XIV. Late Antiquity: Empire and Successors, A. D. 425 - 600, Cambridge, pp. 135-163.

Michael, W., 2000, «Government and Administration», en A. Cameron, B.Ward-Perkins, M. Whitby (eds.), The Cambridge Ancient History. Volume XIV, pp.164-206.

Mohrmann, C., 1961a, «Le latin comun el le latin des chrétiens», Études sur le latin des chrétiens. T. I. Le Latin des chrétiens, Roma, pp. 67-126.

— 1961b, «Étude de la latinité chrétienne», Études sur le latin des chrétiens. T. I pp. 83-102.

— 1961c, «Latin langue de la chrétienté occidentale», Études sur le latin des chrétiens. T. I, pp. 51-81.

— 1961d, «Medieval Latin and Western civilization», Études sur le latin des chrétiens,; T. II. Latin chrétien et médiéval, pp.155-179.

— 1961e, «Quelques traits caractéristiques du latin des chrétiens», Études sur le latin des chrétiens, T. I, pp. 21-50.

— 1961f, «Relations entre langue et religion», T.I, pp.123-137.

Paschoud, F., 1967, Roma Aeterna. 'Études sur le patriotisme romain dans l'Occident latin a l'époque des grandes invasions, Roma.

Syme, R., 1958, «Imperator Caesar: a study in nomenclature», Historia 7, pp. 172-188. 